\title{
SENSORIAMENTO REMOTO APLICADO NA DETECÇÃO DE ÁREAS DEGRADADAS PELA MINERAÇÃO NO SUL DO BRASIL ENTRE 1985 - 2011
}

\author{
Fernando Alves Cantini Cardozo ${ }^{1 *}$, Matheus Montes Pimenta ${ }^{1}$, Rafael R. Ribeiro ${ }^{2}$ \\ 1 Departamento de Engenharia de Minas, UFRGS, 91509-900, Porto Alegre, Brasil \\ 2 Departamento de Geodésia, UFRGS, 91509-900, Porto Alegre, Brasil \\ *E-mail: fernando.cantini3@hotmail.com
}

Recebido em: 23/03/2016

Aceito em: 10/06/2016

\section{RESUMO}

A análise multitemporal de imagens foi aplicada a uma antiga mina abandonada localizada em Minas do Camaquã, no sul do Brasil, entre latitude $-30,908591$ e longitude $-53,446582$, para verificar a relação entre a área degradada durante o funcionamento da mina e a área de recuperação da vegetação após anos de sua desativação. Uma série temporal de imagens do satélite Landsat foi classificada pelo Índice de Vegetação por Diferença Normalizada (NDVI, sigla de Normalized Difference Vegetation Index) para produzir três mapas de uso da região. A partir das comparações entre os referidos mapas e as áreas sem cobertura vegetal, foi possível quantificar a modificação em cada porção da paisagem, identificando-se a evolução das mudanças na área de vegetação natural. Verificou-se que no período 1985 a 1996 a degradação aumentou em 8\%, ou 47,43 ha. Em contrapartida, em 2011 (o último ano analisado) observou-se que a cobertura vegetal foi superior ao primeiro período analisado, ou seja, ocorreu uma recuperação da vegetação de $26 \%$ ou 113,22 ha em relação a 1985.

Palavras-chave: Sensoriamento remoto. Mineração. Área degradada. NDVI.

\section{Introdução}

Após o advento do primeiro satélite de sensoriamento remoto (Landsat 1), em 1972, elaborar mapas precisos sobre o uso e ocupação do solo, alterações na cobertura vegetal, monitoramento ambiental, gestão de recursos naturais e desenvolvimento urbano tornou-se relativamente mais simples, permitindo a realização de inúmeros estudos conciliando pesquisas de campo e dados de satélite em diversas regiões, como áreas urbanas, agrícolas, e, no caso de áreas inacessíveis, sendo o único método de obtenção de dados para aplicação de técnicas de Sistema de Informação Geográfica (SIG) e Sensoriamento Remoto (SR) na observação de alterações periódicas [1] na superfície da Terra.

Embora esta tecnologia esteja disponível a muitos anos, o uso do sensoriamento remoto para monitoramento das atividades de mineração tem sido raramente aplicado, ainda que, segundo KORUYAN et al [2], esta ferramenta tenha se mostrado valiosa na gestão e planejamento de alguns aspectos na operação de empreendimentos mineiros.

Detecção de mudanças em sensoriamento remoto, é descrita por SINGH [3] como "um processo de identificação das diferenças no estado de um objeto ou fenômeno observando-o em períodos diferentes", determinando como atributos específicos de uma área em particular mudaram entre dois ou mais intervalos regulares de tempo, comparando fotografias aéreas ou imagens de satélite da área, obtidas em momentos diferentes. Em geral, detecção de mudanças nas características da superfície terrestre, segundo LU et al [4], fornecem a base para uma melhor compreensão das relações e interações entre os fenômenos naturais e humanos, auxiliando no manejo e gestão dos recursos; e invariavelmente, isto implica na aplicação de análise multitemporal de imagens.

Neste estudo de caso foi examinado o impacto da expansão de áreas degradadas pela produção mineral e as mudanças subsequentes na vegetação natural, ao longo de um período de 26 anos em uma região afetada pela mineração de cobre por mais de um século, gerando impactos ambientais, sociais e econômicos em Minas do Camaquã, no município de Caçapava do Sul, Rio Grande do Sul, Brasil. Usando técnicas de sensoriamento remoto, as áreas degradadas e recuperadas por vegetação pós-mineração foram calculadas com base na análise multiespectral e sequencial de imagens de satélite do índice de vegetação por diferença normalizada (NDVI).

Adotou-se como parâmetro de seleção de imagens: (1) o período em que se tinha disponibilidade dos dados (o satélite 
Landsat 5 foi lançado em 1984 e desativado em 2013), (2) qualidade da imagem que possibilitasse a aplicação do índice de vegetação e (3) representatividade face aos eventos históricos na região.

i. 1985: quatro anos após a mina iniciar operação moderna e mecanizada;

ii. 1996: ano de desativação e abandono da área;

iii. 2011: um ano antes do início das atividades de ecoturismo.

\section{Materiais e Métodos}

Com o objetivo de verificar o impacto ambiental e detectar a evolução das mudanças na cobertura vegetal em uma área de mineração abandonada, técnicas de sensoriamento remoto foram aplicadas na análise de uma série temporal de imagens. Para a aquisição dos dados, as coordenadas da área de estudo (descrita na seção 2.3) e imagens do satélite Landsat 5 (que possui resolução espacial de $30 \mathrm{~m}$ nas bandas do visível e do infravermelho) foram coletados durante 3 períodos diferentes, sendo agosto de 1985, junho de 1996 e abril de 2011 e em seguida zonas de abrangência do impacto foram determinadas com base na área de influência da mineração, incluindo todas as instalações da mina, barragens e cidade mineira. Finalmente a área degradada e em particular as alterações na cobertura vegetal foram quantificadas.

A sequência das análises é mostrada no fluxograma da Figura 2, e cada passo e processamento das imagens são explicados com mais detalhes nas seções a seguir.

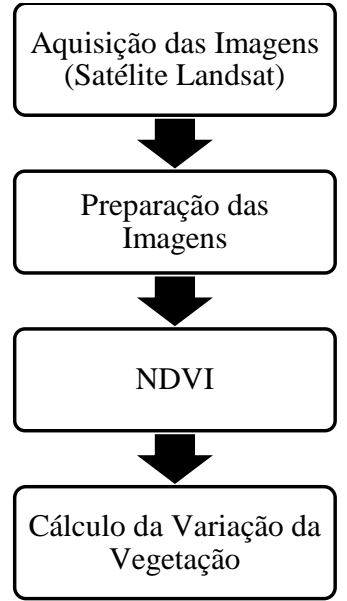

Figura 1 - Fluxograma para cálculo da variação da vegetação.

\section{1 Área de estudo}

A área de estudo situa-se entre latitude -30,908591 e longitude $-53,446582$ e faz parte do Escudo Sul Rio-grandense, distrito de Caçapava do Sul. A descoberta de minério de cobre na região é datada de 1865 e houve vários ciclos de operação e desativação, até a Segunda Guerra Mundial.

Em 1942 foi fundada a Companhia Brasileira do Cobre - CBC, com a participação do Governo do Estado, da Laminação Nacional de Metais e de proprietários e concessionárias das minas. Sua fundação surgiu da necessidade de produzir materiais estratégicos, entre eles o Cobre, durante a guerra. Em 1952 o Grupo Pignatari assumiu o controle acionário da empresa, vendendo-a ao Governo Federal, através do Banco Nacional de Desenvolvimento Econômico e Social (BNDES), vinte e dois anos depois, em razão de dificuldades financeiras e em 1975 a exploração foi suspensa, dadas as condições deficitárias de lavra em subsolo, que havia chegado a 150 metros de profundidade, e a desativação da metalurgia que utilizava o cobre produzido em Minas do Camaquã. Neste período, a CBC direcionou suas atividades para a pesquisa geológica, visando desenvolver a caracterização do minério e ampliação das reservas, permitindo assim, a implementação do chamado "Projeto Expansão Camaquã". As atividades de mineração foram retomadas em 1981 e técnicas de extração altamente mecanizadas passaram a ser utilizadas, tanto nas minas subterrâneas (São Luiz e Uruguai) quanto na frente de lavra a céu aberto da Mina Uruguai. Em 1987, o BNDES assume a totalidade do endividamento bancário da empresa e em 1988 a CBC é colocada em leilão, não tendo sido arrematada por nenhuma das empresas qualificadas por desistência das mesmas. Como uma solução alternativa, a CBC acaba sendo comprada por seus próprios funcionários, que vieram a constituir uma nova empresa. A Bom Jardim S.A. assumiu o comando das atividades, saldou sua dívida com o BNDES, antes do prazo estipulado no Protocolo de Intenções, e continuou a minerar o cobre até maio de 1996, quando ocorreu o esgotamento total das reservas economicamente viáveis conhecidas (PAIM, P.) [5].

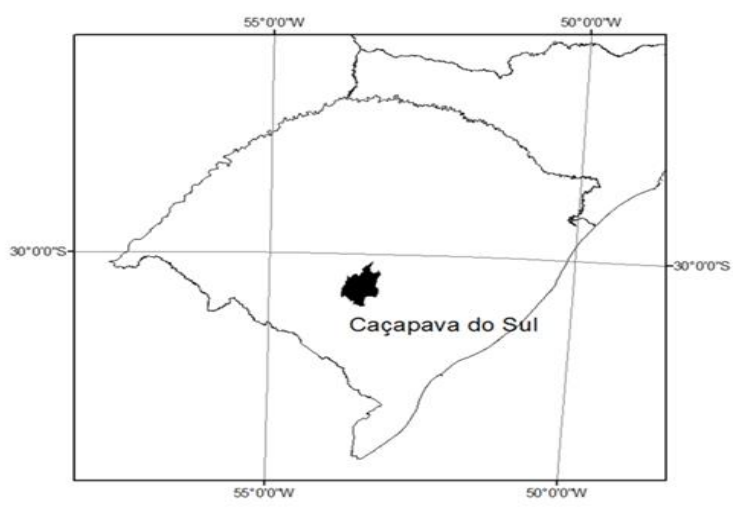

Figura 2 - Localização da área de estudo. 


\subsection{Processamento de imagens}

Para realização deste estudo foram empregadas imagens do satélite Landsat 5, estas obtidas no banco de imagens no site do Instituto Nacional de Pesquisas Espaciais (INPE) [6]. As imagens foram processadas nos softwares ArcGis e ERDAS. Os limites mineração e degradação foram determinados no intervalo temporal utilizando processamento digital de imagem. Após a delimitação da zona de estudo e do recorte da mesma, foi aplicado o Índice para Vegetação (IV) disponível no próprio ERDAS.

\subsection{Estimativa da mudança na vegetação}

Os Índices de Vegetação (IV) são computados e calculados a partir do valor numérico do brilho, neste trabalho será utilizado o índice de vegetação por diferença normalizada (NDVI), que além de mapear, também permite medir sua quantidade e condição.

O NDVI é calculado utilizando as porções da energia eletromagnética refletida pela vegetação nas bandas do vermelho (comprimento de onda $=0,6$ micrômetros) e do infravermelho próximo (comprimento de onda $=0,8$ micrômetros). É o produto de uma função que leva como parâmetros de entrada as bandas espectrais do vermelho e infravermelho. As reflectâncias das bandas 3 (vermelho - visível) e 4 (infravermelho - próximo) do sensor LANDSAT 5, as quais são determinadas pela equação (1) apresentada abaixo (RAMOS) [7]:

$\rho_{0, i}=\frac{L_{r a d} * \pi}{E_{0, i} * \cos \theta * d_{r}}$

Onde $\rho_{0, \mathrm{i}}$ é a reflectância espectral na banda $\mathrm{i} ; \mathrm{d}_{\mathrm{r}} \mathrm{o}$ inverso do quadrado da distância Terra-Sol em unidade astronômica, $\mathrm{E}_{0, \mathrm{i}}$ é o valor médio da irradiância solar exoatmosférica na banda $\mathrm{i}$ em W. $\mathrm{m}^{-2} \mu \mathrm{m}^{-1}$ (constante solar), $\theta$ o ângulo zenital solar (calculado a partir da informação do ângulo de elevação solar, $\beta$, disponível no arquivo cabeçalho da imagem: $\left.\theta=\left(90^{\circ}-\beta\right)\right)$ e Li é a radiância espectral na banda i em $\mathrm{Wm}^{-2} \mathrm{sr}^{-1} \mu \mathrm{m}^{-1}$.

O NDVI foi determinado pela equação (2) a seguir:

$N D V I=\frac{\rho i v-\rho v}{\rho v+\rho v}$

Onde $\rho_{\mathrm{iv}}$ e $\rho_{\mathrm{v}}$, onde representam respectivamente a reflectância nas bandas do infravermelho e vermelho.

Como resultado da aplicação da Equação 2, o produto gerado é carimbado com os valores do NDVI que variam dentro do intervalo de $-1 \mathrm{a}+1$, sendo -1 representação de ausência total de vegetação e +1 presença máxima detectada de vegetação.

\section{Resultados e discussões}

Processadas as imagens e gerados os índices NDVI, foi estipulado o ponto de corte em 0,30 para vegetação e não vegetação. Sendo assim, tudo acima de 0,30 considerado como vegetação e igual ou abaixo disso não vegetação.

Na Figura 3 é possível observar a dinâmica da variação de vegetação na área de estudo, caracterizada por uma retração da mesma entre os períodos de 1985 a 1996, período de atividade da mina, e por fim, expansão da área vegetada no período de 1996 a 2011, período pós desativação da mina e abandono da área.

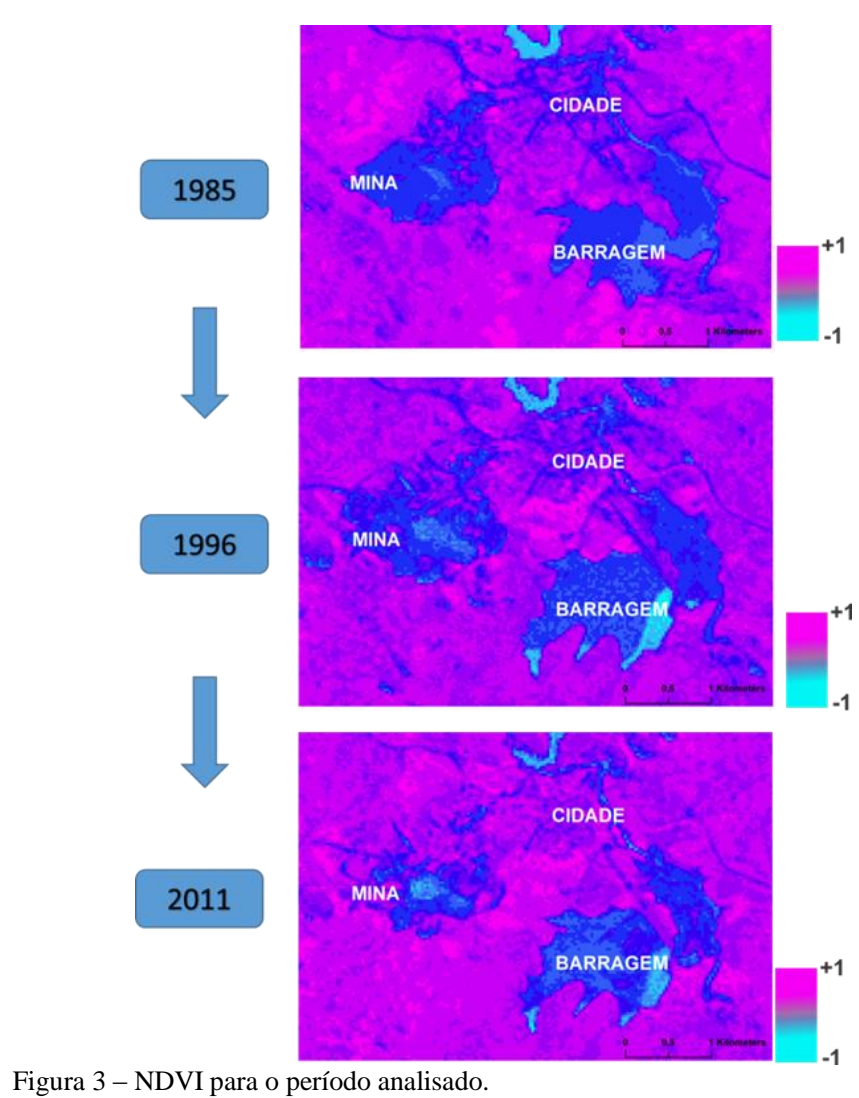

Através da análise do índice NDVI, estipulando o corte em 0,30 foi calculado no próprio software ERDAS a contagem de pixels de vegetação (NDVI > 0,30) e de área degradada $(\mathrm{NDVI} \leq 0,30)$, como a imagem do satélite tem uma resolução espacial de $30 \mathrm{~m}$, a área de cada pixel corresponde a $900 \mathrm{~m}^{2}$. 
Dados apresentados na Tabela 1 e 2. Contabilizando a variação das áreas correspondentes a vegetação e não-vegetação espacialmente, verifica-se um aumento de $26 \%$ de vegetação,em relação ao ano de 1995, ano de menor cobertura vegetal detectado. Com $8 \%$ menos vegetação do que o ano de 1985 . Tabela 1 - Cálculo da área degradada e vegetada entre 1985 e 2011.

\begin{tabular}{ccc}
\hline \multirow{2}{*}{ Área $\left(\mathbf{m}^{2}\right)$} & \multicolumn{2}{c}{ Área $\left(\mathbf{m}^{2}\right)$} \\
\cline { 2 - 3 } & Degradada & Vegetação \\
\hline 1985 & 5825700 & 15486300 \\
1996 & 6300000 & 14896800 \\
2011 & 4693500 & 16785000 \\
\hline
\end{tabular}

Tabela 2 - Cálculo da variação de área degradada entre 1985 e 2011.

\begin{tabular}{cccc}
\hline Período & Variação $\left(\mathbf{m}^{\mathbf{2}}\right)$ & $\begin{array}{c}\text { Variação } \\
\text { Acumulada } \\
\left(\mathbf{m}^{\mathbf{2}}\right)\end{array}$ & $\begin{array}{c}\text { Variação } \\
(\boldsymbol{\%})\end{array}$ \\
\hline $\mathbf{1 9 8 5} \mathbf{- 1 9 9 6}$ & 474300 & 474300 & 8 \\
$\mathbf{1 9 9 6} \mathbf{- 2 0 1 1}$ & -1606500 & -1132200 & -26 \\
\hline
\end{tabular}

A Figura 4 apresenta um gráfico com a evolução da área degradado no período analisado, na qual fica clara a retomada da vegetação sobre a área degradada no período de 1996 a 2011.

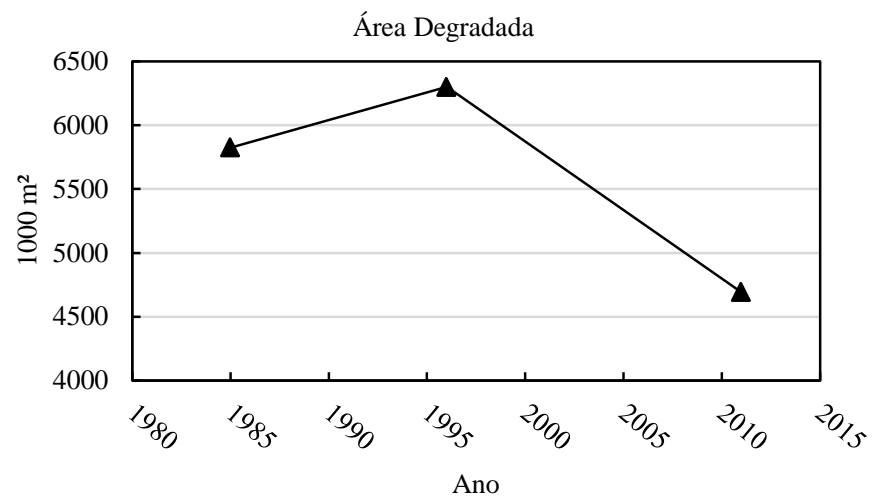

Figura 4- Variação na área degradada.

Na Figura 5 é apresentada a área correspondente à cava da mina a céu aberto isoladamente das demais estruturas que compõe a mineração, esta análise corresponde a vetorização da área marcada como degradada a partir do NDVI. A imagem corresponde a uma composição colorida do ano de 2011 (RGB 542), sobre a qual está representada em amarelo os limites de degradação do ano 1996 e em preto do ano 1985.

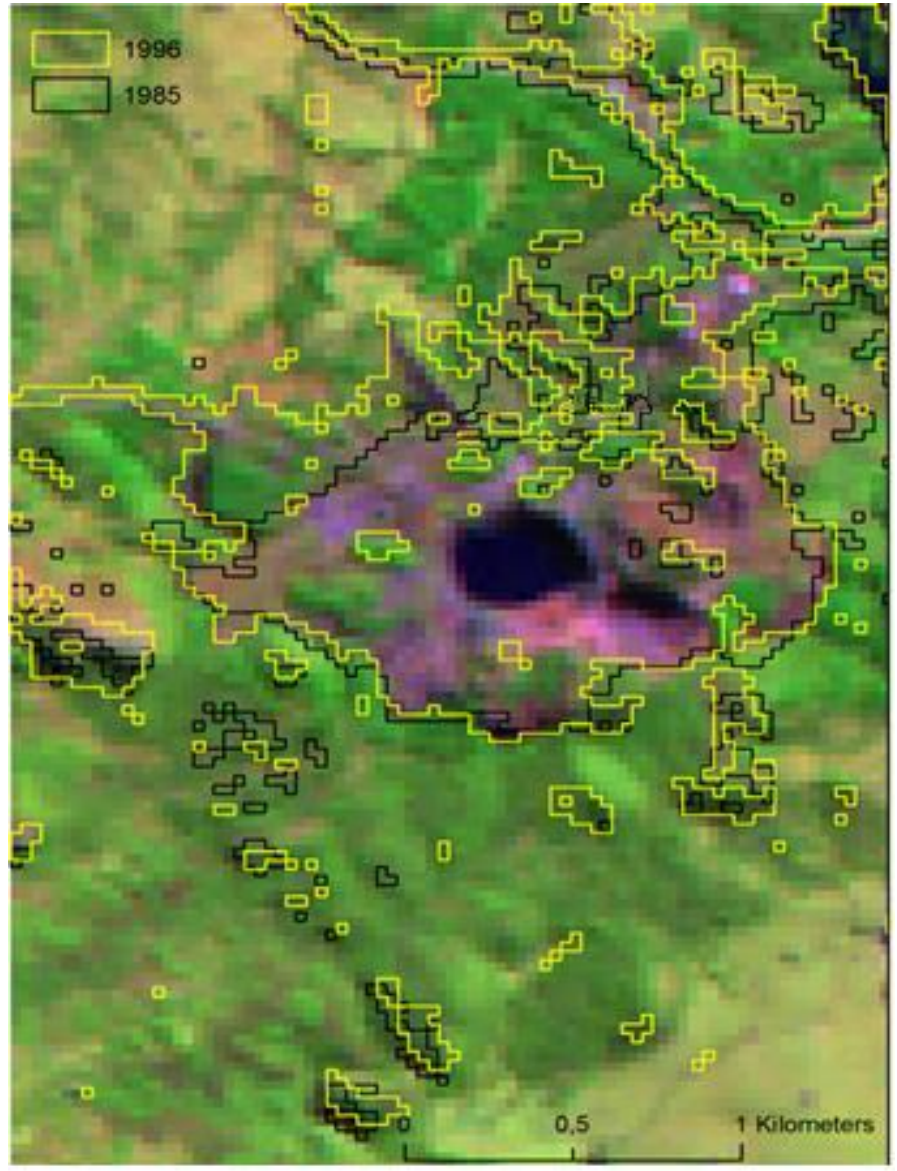

Figura 5 - Composição colorida da área da Mina no ano de 2011(RGB 542), em amarelo os limites de degradação do ano de 1996 e em preto do ano de 1985.

\section{Conclusões}

Uma rápida revisão da literatura mostra que métodos de sensoriamento remoto podem ser aplicados para classificar os tipos de uso da terra de uma forma prática, econômica, repetitiva, e em grandes áreas. Embora técnicas de detecção de mudanças tenham sido amplamente utilizadas em estudos multidisciplinares científicos para monitorar e avaliar os impactos dos processos naturais e da atividade humana sobre o meio ambiente, poucos estudos tem sido realizados para avaliar alterações sobre áreas ocupadas pela mineração empregando estas ferramentas.

Nesta pesquisa, os autores apresentaram uma estimativa da expansão da área degradada e as mudanças na vegetação associadas a atividade mineira através da análise multitemporal entre os anos 1985, 1996 e 2011, aplicando o índice NDVI.

Observou-se que a área sem cobertura vegetal aumentou entre os anos de 1985 e 1996, e que houve grande expansão da vegetação após o encerramento das operações e abandono da área no ano de 1996, avanço este da ordem de $26 \%$ sobre a área 
caracterizada como degradada, sendo no ano de 2011 a área com cobertura vegetal superior a primeira data analisada. Totalizando assim, uma área com cerca de 113 ha. Cabe salientar que estes são dados da área de influência impactada pela mineração como um todo, incluindo a construção da cidade mineira (expansão urbana), barragem de rejeitos e cava a céu aberto. Ao analisarmos apenas a região de influência da cava, visualmente é possível notar uma grande recobertura vegetal.

O esgotamento de recursos minerais é acontecimento comum ao longo da história mundial, porém o abandono e empobrecimento de tais regiões não é uma consequência inevitável (RONCHI) [8]. O uso de sensoriamento remoto e Sistema de Informação Geográfica tem um papel cada vez maior na gestão de áreas de mineração. Juntos, eles fornecem informações e dados estatísticos para avaliação da diversidade de habitat e a mudança da cobertura da terra enquanto a mina está em operação, que poderão ser usados para formular políticas e diretrizes de gestão da área pós-mineração, no planejamento de fechamento de mina, recuperação ambiental, monitoramento, caracterização da paisagem e alternativa socioeconômica para reinserção da área no sistema produtivo. Nesta área de estudo, o munícipio adota desde 2012 o ecoturismo como alternativa para a utilização da área.

Como trabalhos futuros, sugere-se (1) a classificação dos diferentes tipos de cobertura vegetal que ocupam a área por exemplo: vegetação densa, pastagem, vegetação rasteira, vegetação nativa e vegetação exótica, etc; (2) análise multitemporal na sub-bacia do arroio João Dias, a fim de identificar alterações nas condições de seca e contaminação dos sedimentação, visto que o mesmo recebeu os rejeitos sólidos e efluentes líquidos provenientes do tratamento do minério de cobre desde o século XIX, até a construção da barragem de rejeitos no final dos anos 1970; (3) identificação da variação na média do índice de vegetação apenas na área da cava da mina e (4) inclusão de imagens atualizadas e de satélites mais modernos nas análises.

\section{Agradecimentos}

Os autores agradecem a UFRGS pela estrutura oferecida durante a realização deste trabalho, ao INPE pela disponibilização gratuita das imagens e ao professor Rafael Ribeiro pelo apoio, confiança, orientação, incentivo e motivação incondicional que sempre nos impulsionaram em direção às vitórias diante dos desafios que surgiram.

\section{REMOTE SENSING APPLIED IN THE DETECTION OF AREAS DEGRADED BY MINING IN SOUTHERN BRAZIL BETWEEN 1985-2011}

ABSTRACT: The multi-temporal image analysis is one of the most convenient and useful ways to determine how specific attributes of a particular area have changed between two or more regular intervals, comparing aerial photographs or satellite images of the study area taken at different times. This study examined the impact of the expansion of degraded areas through the mineral production and subsequent changes in natural vegetation after leaving the area over a period of 26 years in a region affected by copper mining over a century generating environmental, social and economic impacts in Minas do Camaquã in southern Brazil, using geographic information system (GIS) and remote sensing (RS) techniques. A series of Landsat images were classified by normalized difference vegetation index (NDVI) to produce three land cover maps of the region. From comparisons between these maps and areas with no vegetation cover, it was possible to quantify the variation that occurs in the landscape, identifying the evolution of changes in natural vegetation area. It has been observed that between 1985 and 1996 the degraded area has increased 8\%, however, in 2011 (the last year analyzed), there was greater vegetation cover than in the first reporting period resulting in vegetation recovery of $26 \%$ when compared to 1985 .

Keywords: Remote sensing. Mining. Degraded Area. NDVI.

\section{Referências}

[1] BISWAJIT M. Land use and land cover change detection study at sukinda valley using remote sensing and GIS, 2010.

[2] KORUYAN K., DELIORMANLI A.H., KARACA Z., MOMYEZ M., LU H., and YALÇIN E., Remote sensing in management of mining land and proximate habitat, The Journal of The Southern African Institute of Mining and Metallurgy 122 (2012) 667-672.

[3] SINGH, A. Digital change detection techniques using remotely sensed data, International Journal of Remote Sensing v. 10, n. 6, (1989) 989-1003.

[4]D. LU, E. MORAN, S. HETRICK and LI, G. Land-use and land-cover change detection, Advances in Environmental Remote Sensing, Q. Weng, ed. Taylor \& Francis, Inc. (Chapter 11) (2010) 273-288.

[5] PAIM, P. Minas do Camaquã, RS: Marco da história da mineração de cobre no Brasil. (2002, p. 503). Disponível em:

<http://sigep.cprm.gov.br/sitio064/sitio064.pdf>. Acesso em: 01 de jun. 2016.

[6] Banco de Imagens da DGI/INPE. Instituto Nacional de Pesquisas Espaciais (INPE). Disponível em: <http://www.dgi.inpe.br/CDSR/>. Acesso em: 10 de out. 2015 


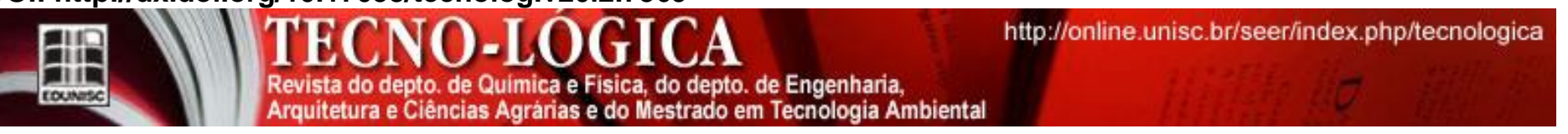

[7] RAMOS, R. R. D. et. al. Aplicação do Índice por Diferença Normalizada (NDVI) na Avaliação de Áreas Degradadas e Potenciais para Unidades de Conservação. In: III SIMPOSIO DE CIENCIAS GEODESICAS E TECNOLOGIA DA GEOINFORMAÇÃO. Anais Recife - 2010.

[8] RONCHI L. H., LOBATO A. O. C., Minas do Camaquã, um estudo multidisciplinar. - São Leopoldo: Ed. UNISINOS, (2000). 366p. 